\title{
Is There an Association between Social Connectedness, Social Identity, Alcohol Consumption and Mental Health among Young University Students?
}

\author{
Kristen Hunt, Sharyn Burns \\ Collaboration for Evidence, Research and Impact in Public Health, School of Public Health, Curtin University, \\ Perth, Australia \\ Email: s.burns@curtin.edu.au
}

How to cite this paper: Hunt, K. and Burns, S. (2017) Is There an Association between Social Connectedness, Social Identity, Alcohol Consumption and Mental Health among Young University Students? Open Journal of PreventiveMedicine, 7, 99-114. https://doi.org/10.4236/ojpm.2017.76009

Received: May 17, 2017

Accepted: June 24, 2017

Published: June 27, 2017

Copyright $\odot 2017$ by authors and ScientificResearch Publishing Inc.

This work is licensed under the

CreativeCommons Attribution

International

License (CC BY 4.0).

http://creativecommons.org/licenses/by/4.0/

\begin{abstract}
Social connectedness has been identified as a protective factor for a range of health issues however the literature is not conclusive. The high prevalence of hazardous alcohol consumption and mental health problems among university students along with the potential for the university as a setting for health promotion prompted this study. The study aims to explore the association between levels of alcohol consumption, mental health, social connectedness and social identity among university students. Online data were collected from a random sample of university undergraduate students $(n=2506)$ aged 18 - 24 years old. Outcomes were measured using the Alcohol Use Disorders Identification Test (AUDIT), the Kessler Psychological Distress Scale, Social Connectedness Scale, Social Identity Scale and measures of paid employment and study (hours), and participation in sports and other clubs. The majority of students had consumed alcohol in the last 12 months (87\%). Of these students $38 \%$ reported to drink at hazardous levels (AUDIT $\geq 8$ ). When all factors were considered: gender, living arrangements, being a domestic student, hours spent at work, participation in university and community sport, higher levels of psychological distress, higher levels of social connectedness, and lower levels of social identity were significant predictors of hazardous alcohol consumption. The finding highlights the need for the inclusion of integrated, multi-strategy health promotion interventions on campus. Further exploration of the associations between social connectedness and social identity as influences of health behaviors will better inform the development of targeted strategies for specific groups.
\end{abstract}

\section{Keywords}

Alcohol, University, Students, Mental Health, Social Connectedness, Social 
Identity

\section{Introduction}

Internationally, a high prevalence of risky alcohol consumption among university populations is commonly reported [1] [2] [3] [4]. Furthermore university students have been found to report higher levels of alcohol consumption than their non-student peers [5]. Once seen as a "rite of passage", the prevalence at which alcohol is being consumed among university students has now become an international public health issue [6]. Factors influencing the high levels of alcohol consumption include: the beginning of new peer networks; access to affordable alcohol on campus; stress related to studies; and the high number of events on campus where alcohol is available [7]. Commonly reported motivators for drinking among students can be categorized as social [8], coping [9] and conformity motives [6] [10]. For example amongst students, consuming alcohol has been linked to reducing anxiety involved in social situations and to improve their attractiveness to others [11], a way of reducing or escaping negative emotions such as stress, anger or conflict [11] [12] and to fit in with peers [6] [10]. In Australia, males [4] and domestic students have been reported to be most at risk of consuming alcohol at harmful levels [4] [13]. Despite these finding, recent studies have indicated that female and male drinking levels among this target group are converging [13] [14].

As well as consuming alcohol at high levels, university students commonly present with mental health problems such as stress, anxiety and depression [4] [15] [16]. The onset of mental health issues is typically seen around the age at which young adults are completing higher education [17]. Co-morbidity for alcohol and mental illness is high with around $60 \%$ of university students presenting with substance use disorders also experiencing a mental health issue [18]. Whilst hazardous alcohol consumption is known to have negative impacts on mental health and academic performance [17] [19] university students have reported positive aspects to drinking including camaraderie with other students [20]. Furthermore, enjoyment and moderate drinking can help relieve stress and therefore help students achieve good mental health [21].

Social connectedness refers to the relationships an individual has with others [22], and can include relationships developed at home, school, work, special interest groups and within sporting groups. The need to belong and form social bonds is a significant motivator of behavior [22].

Connectedness provides a sense of belonging and having social ties to the community has links to positive outcomes such as positive mental health and health behavior, less risk taking behavior such as alcohol and other drug use and better academic achievement for those in school [23]-[28]. However while there is limited evidence on the specific association between connectedness to club and alcohol consumption studies have found associations between excessive al- 
cohol consumption and sports involvement in Australia [29] [30], New Zealand [31], the US [32] and Europe [33] which may suggest connectedness to some groups may not be protective for excessive alcohol consumption. Consistent with these findings, social identity, which refers to how someone identifies with the people and groups around them, at what level they feel they belong to that group and what value or importance they place on that group [34] has been identified as a predictor of intentions to binge drink, especially for those who strongly identify with the group [35].

The university setting provides a unique environment for students to become involved in clubs and groups while forming strong social bonds with others [7] [36]. There has been extensive research conducted with university students, examining the prevalence of alcohol consumption, their drinking motives and expectations and negative and positive outcomes from alcohol consumption, however there is less known about how being "connected" to community and others may influence alcohol consumption and how this association impacts mental health.

This paper compares key factors for low risk and hazardous drinkers from a random cross sectional sample of 18 - 25 years old Western Australian university students. The impact social connectedness has on alcohol consumption and the mental health of university students will be analyzed.

\section{Methods}

Quantitative data were collected from a random cross sectional sample of undergraduate students aged 18 to 24 years, enrolled at the main university campus. This study was approved by the Curtin University Human Research Ethics Committee (HR 54/2013).

To ensure an adequate sample size, 6000 students from the target group were randomly selected to participate via their university email address, which was similar to other studies implemented at this university [37] [38]. The initial email coincided with the release of semester one results. Two follow up emails were sent to the students after the initial invitation. Responses were received from 1825 students (30.4\% response rate).

A further 706 students were randomly recruited via intercept. Research assistants from the Collaboration for Evidence, Research and Impact in Public Health were recruited, completed a standardized one hour training session delivered by the project staff and subsequently administered the survey. Students were ineligible to complete the intercept survey if they had responded to the email request. The questionnaires were administered for both the online and intercept survey through an online self-report questionnaire. Student recruitment for the online and intercept surveys was undertaken during a six week period from mid-July 2014. Students were excluded from completing the face-to-face survey if they had completed the online survey.

Demographic data were collected for age, gender, nationality, Faculty (Business, Engineering and Science, Health Science, Humanities or Centre for Abori- 
ginal Studies), place of residence while at university (living in a shared house, with a parent or guardian, as a boarder, alone, or with partner/children), and year of study.

Previously validated and reliable scales were included in the questionnaire. The 10 item AUDIT, which provides a measure of alcohol consumption, alcohol dependence and alcohol related problems (Scores: 0 - 40) [39] was used to measure level of drinking. AUDIT has been widely used to measure drinking levels on a population basis [1] [5] [40] [41]. Similar to other studies of this population AUDIT was computed to a binary variable to represent low risk $(<8)$ and hazardous levels of alcohol consumption ( $\geq 8)$ [4] [42] [43] [44] [45].

The Kessler Psychological Distress Scale (K10) measures the level of an individual's distress, based on a five level response scale (Scores 10 to 50). The higher the score the higher the level of distress. Scores were computed to represent no or low levels of distress (10 - 19); mild levels of distress (20 - 24); moderate levels of depression/and or anxiety (25 - 29) and high levels of depression/or and anxiety (31 - 50) [46]. The social connectedness scale includes eight items consisting of a six level rating system ( $1=$ agree to $6=$ disagree $)$; measuring connectedness (4 items), companionship (3 items) and affiliation (1 item). Higher scores reflect a higher level of social connectedness [47]. The social identity scale uses a five level rating system ( $1=$ very much to $5=$ not applicable); higher social identity scores reflect a lower level social identity with the people around them [46].

Students were asked how many hours they spent in paid work, attending university classes and doing personal study each week. Responses included: "none", "1 - 5 hours", "6 - 10 hours", "11 - 20 hours" and "20+ hours". For analysis responses were collapsed into three categories (None, 1 - 10hours and 11 - 20+). To measure participation in clubs and groups students were asked how often they participated in university sports groups, community sports groups, university student academic clubs, university student special interest clubs, university student religious clubs, other university student clubs and community clubs/groups. Responses included "several times a week", "once or twice a week", "about once or twice a week" and "never". For analysis responses were collapsed into two categories of "never" and "once a month or more".

The final questionnaire was tested for content and face validity [48] with an expert panel of health promotion and alcohol prevention experts $(n=7)$ and a purposive sample of the target group $(n=60)$. Univariate and bivariate analysis was conducted. Univariate relationships between the independent variables and the dependent variable of low risk and hazardous drinking were described. Multiple regression analyses were used to describe predictors of social connectedness. Data analysis was conducted using SPSS v20.

Descriptive statistics were used to describe the sample. The dependent variable for the analysis was low risk $(\mathrm{n} \leq 8)$ or hazardous $(\geq 8)$ drinkers. Statistical significance and proportions were compared for categorical variables using Chi-Square analyses. Analysis of Variance (ANOVA) was used to evaluate 
means and statistical differences for continuous variables. Highly and moderately significant differences were measured at $\mathrm{p}<0.001$ and $\mathrm{p}<0.05$ respectively.

Binary logistic regression was used to test for association between independent variables and the dependent variable of low risk or hazardous drinking (AUDIT). Demographic factors included gender (due to low numbers, the "other" gender option was removed from the logistic regression analysis), age, faculty, and international student status. Mediating variables included hours spent per week, at work, in university classes, personal study, participation (never, once a month or more) in university clubs, university sports, community clubs and community sports, K10 score, social identity score and social connectedness score. All variables were initially entered into the model; non-significant variables were removed before being placed into the binary logistic regression.

\section{Results}

Approximately $30 \%(n=1825)$ of the random sample recruited via email completed the online survey. An additional 681 students completed the survey through intercept interviews. A total of 2506 surveys were included in the analysis. The majority of respondents were female $(62.1 \% \mathrm{n}=1504)$, followed by male, $37.5 \%(\mathrm{n}=908)$ and other gender (queer $\mathrm{n}=4$; androgynous $\mathrm{n}=1$; intersex $\mathrm{n}=$ 1 , transgender female to male $=1$; transgender male to female $=2$ ). There was a similar representation of younger (18 - 20 years; $49.9 \%)$ and older students (21 24 years; 50.1\%). Respondents were enrolled in the following Faculties: Health Science (36.2\%), Science and Engineering (22.3\%), Humanities (21.4\%), Business (18.4\%) and the Centre for Aboriginal Studies (0.2\%). The majority of respondents lived with parent/s or guardian/s $(n=1418 ; 60.3 \%)$, followed by sharing a flat or residence $(\mathrm{n}=590 ; 25.1 \%)$; living with a partner and/or children ( $\mathrm{n}$ $=128 ; 5.4 \%)$, or living in student housing $(\mathrm{n}=114 ; 4.9 \%)$. The remainder lived alone $(\mathrm{n}=46 ; 2 \%)$, boarded $(\mathrm{n}=21 ; 0.8 \%)$ and had other arrangements, which consisted of living with siblings or home-stays $(n=33 ; 1.4 \%)$. Approximately ninety percent of the sample classified themselves as Australian ( $n=1709,90.6 \%)$ and 178 (9.4\%) identified as international students.

The majority of the student sample $(n=1905 ; 87 \%)$, reported to have consumed alcohol in the past 12 months. Of the students who completed the AUDIT questions $(n=1887), 38 \%(n=717)$ reported that they consumed alcohol at hazardous levels (AUDIT score of $\geq 8$ ).

Over half of the sample $(61.9 \%, \mathrm{n}=1208)$ reported no or low levels of psychological distress; $28.5 \%$. $(n=556)$ indicated they may be experiencing mild levels of distress, mild depression and/or anxiety disorder. Moderate levels of depression and/or anxiety were reported by $7.6 \%(n=149)$ of students. Only $1.9 \%$ $(n=38)$ of students indicated they may be experiencing severe depression and/or anxiety.

The majority of the sample did not participate in university sports $(82.0 \% \mathrm{n}=$ $1548)$, university clubs $(76.4 \% \mathrm{n}=1441)$, community sports $(65.7 \% \mathrm{n}=1239)$ or community clubs $(68.2 \%, \mathrm{n}=1287)$. The majority of students undertook 11 - 
$20+$ hours of paid employment per week $(48.2 \%, \mathrm{n}=909)$, attended $11-20+$ hours of university classes $(54.1 \%, \mathrm{n}=1020)$, and carried out $1-10$ hours per week of personal study $(73.6 \%, \mathrm{n}=1388)$.

Table 1 shows the results of the initial univariate analysis comparing respondents who reported low risk and hazardous AUDIT scores to key demographic variables. Males (42.5\%) were more likely to participate in hazardous drinking compared to females $(35.2 \%)$. International students $(88.2 \%)(\mathrm{p}<0.001)$ were more likely to participate in low risk drinking behavior. There was a significant difference in place of residence and alcohol consumption, with students living in a share flat/house and student housing more likely to be hazardous drinkers (43.3\%; 48.9\% respectively). There was no significant difference between low risk and hazardous drinking and age, Faculty, years at university, hours spent completing personal study, and participation in university and community clubs.

There was a significant difference between the hours students attended paid employment $(\mathrm{p}<0.001)$; university classes $(\mathrm{p}=0.003)$ and low risk and hazardous drinking. Students who did not participate in paid employment were more likely to report low risk drinking compared to hazardous levels of consumption (69.1\% vs $30.9 \%)$. Students who participated in $11-20+$ hours of paid employment were more likely to report hazardous drinking (43.3\%). Hazardous drinking was similar for respondents who reported attending $1-10$ hours (41.6\%) and $11-20$ hours (36.6\%) of university classes. Only $22.2 \%$ of students who reported attending no classes reported hazardous drinking levels however non-attenders comprised only $7.6 \%(\mathrm{n}=144)$ of the sample. Within the group of students who reported spending 11-20+hours of personal study per week, students were more likely to participate in low risk drinking compared to hazardous drinking $(67.3 \%$ vs $32.7 \%)$. Students who reported no personal study per week were more likely to report hazardous drinking (54.8\%) (Table 1).

There was significant difference between students who participated in university sport $(\mathrm{p}<0.001)$; and community sport $(\mathrm{p}<0.001)$ and level of drinking. Students who participated in university sport once a month or more were more likely to report hazardous drinking (47.5\%) compared to students who did not participate (35.9\%). Students who never participated in community sports were more likely to record low risk drinking compared to hazardous drinking $(66.8 \%$ vs $33.2 \%)$.

Students who reported hazardous drinking reported: higher levels of social connectedness (M 39.09; SD 9.87); higher levels of psychological distress (M16.22; SD5.41); and higher social identity scores, indicating a low level of social identity (M6.92; SD2.13) (Table 2).

When all factors were considered (Table 3$)$ gender $(\mathrm{p}<0.001)$, students' living arrangements $(p<0.001)$, international student status $(p<0.001)$, hours spent at work $(\mathrm{p}<0.001)$, participation in community sport $(\mathrm{p}<0.001)$, the psychological distress $(\mathrm{p}<0.001)$, and social connectedness $(\mathrm{p}=0.001)$ were significant predictors of hazardous drinking, while participation in university sport $(\mathrm{p}<0.05)$ was a moderately significant predictor of hazardous drinking. 
Table 1. Predictors of low and hazardous drinking using univariate analysis (categorical variables).

\begin{tabular}{|c|c|c|c|c|}
\hline Moderators & Low RiskN (\%) & HazardousN (\%) & TotalN (\%) & P Value \\
\hline Gender** & & & & 0.002 \\
\hline Male & $405(57.5)$ & $299(42.5)$ & 704 & \\
\hline Female & $761(64.8)$ & $413(35.2)$ & 1174 & \\
\hline Other & $3(37.5)$ & $5(62.5)$ & 8 & \\
\hline Total & $1169(62.0)$ & $717(38.0)$ & 1886 & \\
\hline Age & & & & 0.007 \\
\hline $18-20$ years & $563(59)$ & $391(41)$ & $954(50.6)$ & \\
\hline $21-24$ years & $607(65.1)$ & $326(34.9)$ & $933(49.4)$ & \\
\hline Total & $1170(62.0)$ & $717(38.0)$ & 1887 & \\
\hline Faculty & & & & 0.116 \\
\hline Health Science & $429(62.5)$ & $257(37.5)$ & $686(36.4)$ & \\
\hline Science and Engineering & $245(59.8)$ & $165(40.2)$ & $410(21.7)$ & \\
\hline Humanities & $285(66)$ & $147(34)$ & $432(22.9)$ & \\
\hline Business & $210(59.2)$ & $145(40.8)$ & $355(18.8)$ & \\
\hline Aboriginal Studies & $1(25)$ & $3(75)$ & $4(0.2)$ & \\
\hline Total & $1770(62.0)$ & $717(38.0)$ & 1887 & \\
\hline $\begin{array}{c}\text { Place of residence while at } \\
\text { university }\end{array}$ & & & & 0.000 \\
\hline Share flat/house & $274(56.7)$ & $209(43.3)$ & $483(25.6)$ & \\
\hline Student housing & $46(51.1)$ & $44(48.9)$ & $90(4.8)$ & \\
\hline Parent/guardian & $728(64.1)$ & 407 (35.9) & $1135(60.2)$ & \\
\hline Live alone & $19(59.4)$ & $13(40.6)$ & $32(1.70)$ & \\
\hline With partner/children & $82(76.6)$ & $25(23.4)$ & $107(5.7)$ & \\
\hline $\begin{array}{l}\text { Board/live with other } \\
\text { relative or friend/other }\end{array}$ & $7(38.9)$ & $11(61.1)$ & $18(0.5)$ & \\
\hline Other & $14(63.6)$ & $8(36.4)$ & $22(1.2)$ & \\
\hline Total & $1170(62.0)$ & $717(38.0)$ & 1887 & \\
\hline Student enrolment & & & & 0.000 \\
\hline International student & $157(88.2)$ & $21(11.8)$ & $178(9.4)$ & \\
\hline Domestic student & $1013(59.3)$ & $696(40.7)$ & $1709(90.6)$ & \\
\hline Total & $1170(62.0)$ & $717(38.0)$ & 1887 & \\
\hline $\begin{array}{l}\text { Hours per week paid } \\
\text { employment* }\end{array}$ & & & & 0.000 \\
\hline None & $282(69.1)$ & $126(30.9)$ & $408(21.6)$ & \\
\hline $1-10$ & $373(65.4)$ & $197(34.6)$ & $570(30.2)$ & \\
\hline $11-20+$ & $515(56.7)$ & $394(43.3)$ & $909(48.2)$ & \\
\hline Total & $1170(62.0)$ & $717(38.0)$ & 1887 & \\
\hline $\begin{array}{l}\text { Hours per week } \\
\text { university classes }\end{array}$ & & & & 0.003 \\
\hline None & $56(77.8)$ & $16(22.2)$ & $72(3.8)$ & \\
\hline $1-10$ & $464(58.4)$ & $331(41.6)$ & $795(42.1)$ & \\
\hline $11-20+$ & $650(63.7)$ & $370(36.3)$ & $1020(54.1)$ & \\
\hline Total & $1170(62.0)$ & $717(38.0)$ & 1887 & \\
\hline $\begin{array}{l}\text { Hours per week } \\
\text { personal study }\end{array}$ & & & & 0.008 \\
\hline None & $14(45.2)$ & $17(54.8)$ & $31(1.6)$ & \\
\hline $1-10$ & $841(60.6)$ & $547(39.4)$ & $1388(73.6)$ & \\
\hline $11-20+$ & $315(67.3)$ & $153(32.7)$ & $468(24.8)$ & \\
\hline Total & $1170(62.0)$ & $717(38.0)$ & 1887 & \\
\hline $\begin{array}{l}12 \text { months participation in } \\
\text { university clubs }\end{array}$ & & & & 0.090 \\
\hline
\end{tabular}




\section{Continued}

\begin{tabular}{|c|c|c|c|c|}
\hline Once a month or more & $289(64.8)$ & $157(35.2)$ & $446(23.6)$ & \\
\hline Never & $881(61.1)$ & $560(38.9)$ & $1441(76.4)$ & \\
\hline Total & $1170(62.0)$ & $717(38.0)$ & 1887 & \\
\hline $\begin{array}{l}12 \text { months participation } \\
\text { university sports* }\end{array}$ & & & & 0.000 \\
\hline Once a month or more & $178(52.5)$ & $161(47.5)$ & $339(18.0)$ & \\
\hline Never & $992(64.1)$ & $556(35.9)$ & $1548(82.0)$ & \\
\hline Total & $1170(62.0)$ & $717(38.0)$ & 1887 & \\
\hline $\begin{array}{l}12 \text { months participation in } \\
\text { community clubs }\end{array}$ & & & & 0.478 \\
\hline Yes & $371(61.8)$ & $229(38.2)$ & $600(31.8)$ & \\
\hline Never & $799(62.1)$ & $488(37.9)$ & $1287(68.2)$ & \\
\hline Total & $1170(62.0)$ & $717(38.0)$ & 1887 & \\
\hline $\begin{array}{l}12 \text { months participation } \\
\text { community sports }\end{array}$ & & & & 0.000 \\
\hline Once a month or more & $342(52.8)$ & $306(47.2)$ & $648(34.3)$ & \\
\hline Never & $828(66.8)$ & $411(33.2)$ & $1239(65.7)$ & \\
\hline Total & $1170(62.0)$ & $717(38.0)$ & 1887 & \\
\hline
\end{tabular}

Significant at $\mathrm{p}<0.001^{*}$; significant at $\mathrm{p}<0.05^{* *}$.

Table 2. Mediators of low and hazardous drinking using univariate analysis (continuous variables).

\begin{tabular}{|c|c|c|c|c|}
\hline & Low & Hazardous & Total & $P$ Value \\
\hline \multirow{3}{*}{ Social connectedness } & M 38.13 & M 39.09 & M 38.50 & \multirow{3}{*}{$\mathrm{P}=0.041$} \\
\hline & SD 9.837 & SD 9.865 & SD 9.856 & \\
\hline & CI37.57 - 38.70 & CI $38.37-39.81$ & CI 38.05 - 38.94 & \\
\hline \multirow{3}{*}{$\begin{array}{l}\text { Psychological distress } \\
\text { (K10 scores) }\end{array}$} & M 15.53 & M 16.35 & M 15.83 & \multirow{3}{*}{$\mathrm{P}=0.001$} \\
\hline & SD 5.131 & SD 5.440 & SD 5.265 & \\
\hline & CI15.22 - 15.81 & CI 15.95 - 16.75 & CI $15.60-16.07$ & \\
\hline \multirow{3}{*}{ Social identity scores } & M 6.71 & M 6.96 & M 6.81 & \multirow{3}{*}{$\mathrm{P}=0.012$} \\
\hline & SD 2.079 & SD 2.133 & SD 2.103 & \\
\hline & CI $6.59-6.83$ & CI $6.81-7.12$ & CI $6.71-6.90$ & \\
\hline
\end{tabular}

1. Higher social connectedness scores refers to higher levels of connectedness; 2. Higher psychological distress scores refers to higher levels of distress, depression/and or anxiety;3. Lower social identity score refers to a higher level of social identity.

Table 3. Effect of predictors on hazardous compared to low risk drinking.

\begin{tabular}{ccccc}
\hline Predictor variables & Odds Ratio & CI & df & P Value \\
\hline Gender - Male & 0.668 & $0.544-0.820$ & 1 & $0.000^{*}$ \\
Live at University & 0.824 & $0.755-0.901$ & 1 & $0.000^{*}$ \\
International student & 5.772 & $3.543-9.403$ & 1 & $0.000^{*}$ \\
Hours spent at work & 1.262 & $1.109-1.436$ & 1 & $0.000^{*}$ \\
Hours spent at university & 0.894 & $0.751-1.065$ & 1 & 0.210 \\
University sports & 1.369 & $1.052-1.780$ & 1 & $0.019^{* *}$ \\
YES/NO & 1.581 & $1.278-1.957$ & 1 & $0.000^{*}$ \\
Community sports & 1.052 & $1.030-1.075$ & 1 & $0.000^{*}$ \\
YES/NO & 1.020 & $1.008-1.033$ & 1 & $0.001^{\star *}$ \\
Psychological distress & 1.053 & $1.002-1.108$ & 1 & 0.043 \\
Social Connectedness & & & \\
Social identity & & & & \\
\hline
\end{tabular}

Significant at $\mathrm{p}<0.001^{*}$; significant at $\mathrm{p}<0.05^{* *}$. 
Australian domestic students were approximately 5.8 times more likely to report hazardous drinking than international students. Students who spent more hours in paid employment were 1.2 times more likely to consume alcohol at hazardous levels. Students who participated in university and community sport were approximately 1.4 and 1.6 times more likely to be hazardous drinkers respectively. Students who reported higher levels of psychological distress, were 1.1 times more likely to consume alcohol at hazardous levels (OR 1.052; CI 1.008 - 1.033) while students who were more socially connected were 1.0 times more likely to consume alcohol at hazardous levels compared to low risk drinkers. Lower levels of social identity was a moderate predictor of hazardous drinking $(\mathrm{p}<0.05)$.

\section{Discussion}

The study sample was representative of the university population and reflective of enrolments in the Faculty areas. The majority of respondents in this study reported to consume alcohol at some level in the past twelve months (87\%) which is consistent with previous university-based research which shows a high prevalence of alcohol consumption among young people [4] [49] [50]. Thirty eight percent of the sample reported to drink at hazardous levels. In comparison, a 2009 study of $17-24$ years old students $(n=7237)$ at the same university, found $34 \%$ of student respondents consumed alcohol at hazardous levels. In this early study hazardous drinking levels were defined by using hazardous AUDIT scores and more than six standard drinks in one sitting during the last month [4]. Another Australian university study found $46.6 \%$ of 18 - 24 years old consumed alcohol at hazardous levels using the same binary analysis of low risk and hazardous AUDIT scores as this study [49]. Similar to other studies, males in this study were more likely to report hazardous drinking than females (males $42.5 \%$ vs females 35.2\%) [4] and when all predictors were considered gender was a significant factor in hazardous alcohol consumption.

Students who lived in a share house or student housing were more likely to consume alcohol at hazardous levels which is similar to a study from New Zealand that found students living in a residence hall or boarding house were more than twice as likely to report hazardous drinking as those living elsewhere [51]. Students who spent more hours per week in paid employment were more likely to consume alcohol at hazardous levels than those with no or few work hours. This outcome is contradictory of a 2010 study that found greater earnings did not promote drinking, however the study did acknowledge that greater earnings could provide students with more money to spend on leisure activities, such as drinking [52].

When all factors were considered identifying as an international student was a significant predictor of low risk drinking. Studies have shown that international students tend to socialize with people whose cultural backgrounds are similar to their own [53] [54]. Of the $90.6 \%$ of domestic students who completed the AUDIT questions, $40.7 \%$ were classified as hazardous drinkers. A 2007 interven- 
tion undertaken at the same university found similar results with males and Australian and New Zealand residents having significantly increased odds of reporting hazardous AUDIT scores compared to females and international students [4].

When considering all factors higher levels of psychological distress was found to be a significant predictor of hazardous alcohol consumption. Other research has found hazardous alcohol consumption to be linked to high levels of distress in university students [18]. Similarly, a study focusing on US and Canadian students ( $\mathrm{n}=71,860 ; \mathrm{n}=107$ Institutions) found alcohol was one of the top ten factors affecting student's mental health and academic performance [55].

Consistent with previous research alcohol consumption was higher among students who participated in community sports $(\mathrm{p}<0.001)$ and university sport $(\mathrm{p}<0.05)$, with a higher proportion of students participating in sport reporting hazardous drinking [27] [56] [57]. Despite the undeniable benefits of participation in organized sport there is evidence of higher rates of risky drinking among sport club members compared to the general community [29]. Adolescents [4], university students [58] and young adults who participate in organized sports, especially team sports [57] [58] are more likely to drink alcohol at more hazardous levels than their non-sporting peers.

The university setting offers many opportunities for students to become connected with others [22]. This study found that high levels of social connectedness predicted hazardous alcohol consumption. The literature regarding social connectedness as a protective factor for health behaviors is not conclusive. While positive associations between school connectedness and mental health have been found [59] social connectedness may increase some risky behaviors [60]. A longitudinal study which followed secondary school students, once at grade 8 (13 14 years old), grade 10 (16 years old), and one year post-secondary school, found students with good school and social connectedness to have the best health outcomes, however those with poor school connectedness but good social connectedness were at a greater risk of mental health problems and engaging in risky health behaviors, such as alcohol and other drug use [60]. While school, family and internal connectedness has been found to decrease tobacco, alcohol and marijuana use, connectedness to friends was found to increase substance use [61]. Adolescent connectedness to community, volunteer and religious groups was found to be protective of harmful alcohol consumption while those who were connected to sports clubs were more likely to consume alcohol at higher levels [4]. This study was interested in exploring the association between connectedness, social identify and alcohol consumption. A moderately significant association between lower levels of social identity and hazardous levels of alcohol consumption was found when all factors were considered. Higher levels of social identity though affiliation with specific groups has found to be protective for mental health problems and to enhance life satisfaction [62] while others have suggested young people's alcohol consumption may be associated with the group to which they are most affiliated [63]. Peers have been found to be a significant 
influence on alcohol consumption with homogeneity of behaviors being common [42]. While peer connections can promote positive social, emotional and behavioral attributes they also have the capacity to influence negative behaviors [64]. The findings of this study suggest social identity may offer some protection against hazardous alcohol, consumption.

There are a number of limitations to consider when interpreting the results of this study. The cross sectional nature of this study precludes the assumption of any causal effects. Females were more likely to participate in the online questionnaire, however this is consistent with previous university studies [4]. Participants were randomly recruited using two different strategies: email invitation and intercept. Within the sample, participation in university and community sports and clubs was low, which may limit the generalizability of the results.

\section{Conclusions}

These findings are consistent with previous research that highlights male and domestic students are at risk for hazardous consumption of alcohol [4]. In addition, this study confirms an association between mental health problems and levels of alcohol consumption and informs the need for the inclusion of mental health strategies on campus.

The context of alcohol consumption, social connectedness and social identity is a pertinent issue for both the university and health practitioners [65]. Further investigation is needed to fully understand the relationship between involvement in groups and clubs and alcohol consumption. Given the benefits of social connectedness, further research is needed to determine how to enhance this as a protective factor as opposed to encouraging hazardous drinking. A better understanding of the association between connectedness, social identity, mental health and alcohol consumption will inform the development of appropriate interventions for young university students.

\section{Acknowledgements}

This study was based at the Collaboration for Evidence, Research and Impact in Public Health. The authors acknowledge participants of this study who gave their time to complete the survey, the Curtin Office for Strategy and Planning and health promotion students for help in administering the survey. This study was supported by Healthway (the Western Australian Health Promotion Foundation) project number 30104.

\section{References}

[1] Karam, E., Kypri, K. and Salamoun, M. (2007) Alcohol Use among College Students: An International Perspective. Current Opinion Psychiatry, 20, 213-221. https://doi.org/10.1097/YCO.0b013e3280fa836c

[2] Saltz, R.F., Welker, L.R., Paschall, M.J., Feeney, M.A. and Fabiano, P.M. (2009) Evaluating a Comprehensive Campus-Community Prevention Intervention to Reduce Alcohol-Related Problems in a College Population. Journal of Studies on Al- 
cohol and Drugs, 16, 21-27. https://doi.org/10.15288/jsads.2009.s16.21

[3] Wechsler, H., Lee, J., Kuo, M., Seibring, M., Nelson, T. and Lee, H. (2002) Trends in College Binge Drinking during a Period of Increased Prevention Efforts. Findings from 4 Harvard School of Public Health College Alcohol Study Surveys: 1993-2001. Journal of American College Health, 50, 203-217. https://doi.org/10.1080/07448480209595713

[4] Hallett, J., Howat, P., Maycock, B., McManus, A., Kypri, K. and Dhaliwal, S. (2012) Undergraduate Student Drinking and Related Harms at an Australian University: Web-Based Survey of a Large Random Sample. BMC Public Health, 12, 37. https://doi.org/10.1186/1471-2458-12-37

[5] Kypri, K., Cronin, M. and Wright, C.S. (2005) Do University Students Drink More Hazardously than Their Non-Student Peers? Addiction, 100, 713-714.

https://doi.org/10.1111/j.1360-0443.2005.01116.x

[6] Murphy, J.G., Hoyme, C.K., Colby, S.M. and Borsari, B. (2006) Alcohol Consumption, Alcohol-Related Problems, and Quality of Life among College Students. Journal of College Student Development, 47, 110-121.

https://doi.org/10.1353/csd.2006.0010

[7] Reifman, A., Ro, H.-S., Barnes, G.M. and Feng, D. (2010) Drinking in Youth Ages 13-21 Attending and Not Attending College. Journal of the First-Year Experience \& Students in Transition, 22, 67-86.

[8] Matthias, W., Emmanuel, K. and Gerhard, G. (2010) Drinking at European Universities? A Review of Students' Alcohol Use. Addictive Behaviors, 35, 913-924.

[9] Carey, K.B. and Correia, C.J. (1996) Drinking Motives Predict Alcohol-Related Problems in College Students. Journal of Studies on Alcohol, 58, 100-105. https://doi.org/10.15288/jsa.1997.58.100

[10] Lee, C., Lee, J., Maggs, C. and Neighbors, M.P. (2011) Positive and Negative Alcohol-Related Consequences: Associations with Past Drinking. Journal of Adoles cence, 34, 87-94.

[11] Larimer, M. (2013) Preventing Alcohol Abuse in College Students: A Harm-Reduction Approach. Alcohol Problems among Adolescents: Current Directions in Prevention Research. 147.

[12] Tavolacci, M.P., Ladner, J., Grigioni, S., Richard, L., Villet, H. and Dechelotte, P. (2013) Prevalence and Association of Perceived Stress, Substance Use and Behavioral Addictions: A Cross-Sectional Study among University Students in France, 2009-2011. BMC Public Health, 13, 1.

[13] O’Brien, K.S., Hunter, J., Kypri, K. and Ali, A. (2008) Gender Equality in University Sports People's Drinking. Drug and Alcohol Review, 27, 659-665. https://doi.org/10.1080/09595230801935664

[14] Connor, J., Connor, A., Gray, A. and Kypri, K. (2010) Drinking History, Current Drinking and Problematic Sexual Experiences among University Students. Australian and New Zealand Journal of Public Health, 34, 487-494. https://doi.org/10.1111/j.1753-6405.2010.00595.x

[15] Blanco, C., Okuda, M.M.D., Wright, C.B.S., Hasin, D.S., Grant, B.F., Liu, S.-M.M.S., et al. (2008) Mental Health of College Students and Their Non-College-Attending Peers: Results from the National Epidemiologic Study on Alcohol and Related Conditions. Archives of General Psychiatry, 65, 1429-1437. https://doi.org/10.1001/archpsyc.65.12.1429

[16] Eisenberg, D., Eisenberg, S., Gollust, E. and Golberstein, J. (2007) Prevalence and Correlates of Depression, Anxiety, and Suicidality among University Students. 
American Journal of Orthopsychiatry, 77, 534-542. https://doi.org/10.1037/0002-9432.77.4.534

[17] Reavley, N. and Jorm, A.F. (2010) Prevention and Early Intervention to Improve Mental Health in Higher Education Students: A Review. Early Intervention in Psychiatry, 4, 132-142. https://doi.org/10.1111/j.1751-7893.2010.00167.x

[18] Armstrong, T.D. and Costello, J.E. (2002) Community Studies on Adolescent Substance Use, Abuse, or Dependence and Psychiatric Comorbidity. Journal of Consulting and Clinical Psychology, 70, 1224.

https://doi.org/10.1037/0022-006X.70.6.1224

[19] Reavley, N.J., Jorm, A.F., McCann, T.V. and Lubman, D.I. (2011) Alcohol Consumption in Tertiary Education Students. BMC Public Health, 11, 545.

https://doi.org/10.1186/1471-2458-11-545

[20] Polizzotto, M.N., Saw, M.M., Tjhung, I., Chua, E.H. and Stockwell, T.R. (2007) Fluid Skills: Drinking Games and Alcohol Consumption among Australian University Students. Drug and Alcohol Review, 26, 469-475.

https://doi.org/10.1080/09595230701494374

[21] El-Guebaly, N. (2007) Investigating the Association between Moderate Drinking and Mental Health. Annals of Epidemiology, 17, S55-S62.

[22] Dowd, A.J., Schmader, T., Sylvester, B., Jung, M., Zumbo, B., Martin, L., et al. (2014) Effects of Social Belonging and Task Framing on Exercise Cognitions and Behavior. Journal of Sport \& Exercise Psychology, 36, 80-92. https://doi.org/10.1123/jsep.2013-0114

[23] Kawachi, I. and Berkman, L. (2001) Social Ties and Mental Health. Journal of Urban Health, 78, 458-467. https://doi.org/10.1093/jurban/78.3.458

[24] Norton, B.L. (2006) Does Community Connectedness Matter? Exploring the Association between Protective Social Factors and Preventive Health Behaviors in a Culturally Diverse, Environmentally Stressed Context. The University of Oklahoma Health Sciences Center, Ann Arbor.

[25] Kuntsche, S., Knibbe, R. and Gmel, G. (2009) Social Roles and Alcohol Consumption: A Study of 10 Industrialised Countries. Social Science \& Medicine, 68, 12631270.

[26] Wagnsson, S., Augustsson, C. and Patriksson, G. (2013) Associations between Sport Involvement and Youth Psychosocial Development in Sweden: A Longitudinal Study. Journal of Sport for Development, 1, 37-47.

[27] Blomfield, C. and Barber, B. (2010) Australian Adolescents' Extracurricular Activity Participation and Positive Development: Is the Relationship Mediated by Peer Attributes? Australian Journal of Educational \& Developmental Psychology, 10, 114-128.

[28] Fredricks, J.A. and Eccles, J.S. (2006) Is Extracurricular Participation Associated with Beneficial Outcomes? Concurrent and Longitudinal Relations. Developmental Psychology, 42, 698.

[29] DrugInfo Clearinghouse (2009) Prevention Research Quarterly: Alcohol and Community Sporting Clubs. DrugInfo Clearinghouse, Melbourne.

[30] Kingsland, M., Wolfenden, L., Tindall, J., Rowland, B., Lecathelinais, C., Gillham, K.E., et al. (2015) Tackling Risky Alcohol Consumption in Sport: A Cluster Randomised Controlled Trial of an Alcohol Management Intervention with Community Football Clubs. Journal of Epidemiology and Community Health, 69, 993-999. https://doi.org/10.1136/jech-2014-204984

[31] O’Brien, K.S., Kolt, G.S., Webber, A. and Hunter, J.A. (2010) Alcohol Consumption 
in Sport: The Influence of Sporting Idols, Friends and Normative Drinking Practices. Drug and Alcohol Review, 29, 676-683. https://doi.org/10.1111/j.1465-3362.2010.00182.x

[32] Eccles, J.S., Barber, B.L., Stone, M. and Hunt, J. (2003) Extracurricular Activities and Adolescent Development. Journal of Social Issues, 59, 865-889. https://doi.org/10.1046/j.0022-4537.2003.00095.x

[33] Lorente, F.O., Souville, M., Griffet, J. and Grélot, L. (2004) Participation in Sports and Alcohol Consumption among French Adolescents. Addictive Behaviors, 29, 941-946.

[34] Christian J, Bagozzi R, Abrams D, Rosenthal H. (2012) Social influence in newly formed groups: The roles of personal and social intentions, group norms, and social identity. Personality and Individual Differences, 52: 3:255-60.

[35] Johnston, K.L. and White, K.M. (2003) Binge-Drinking: A Test of the Role of Group Norms in the Theory of Planned Behaviour. Psychology and Health, 18, 63-77. https://doi.org/10.1080/0887044021000037835

[36] Terenzini, P.T., Rendon, L.I., Lee Upcraft, M., Millar, S.B., Allison, K.W., Gregg, P.L., et al. (1994) The Transition to College: Diverse Students, Diverse Stories. Research in Higher Education, 35, 57-73. https://doi.org/10.1007/BF02496662

[37] Hallett, J., Howat, P., McManus, A., Meng, R., Maycock, B. and Kypri, K. (2013) Academic and Personal Problems among Australian University Students Who Drink at Hazardous Levels: Web-Based Survey. Health Promotion Journal of Australia, 24, 170-177. https://doi.org/10.1071/HE13094

[38] Burns, S.K., Jancey, J., Bowser, N., Comfort, J., Crawford, G. and Hallett, J. (2013) Moving Forward: A Cross Sectional Baseline Study of Staff and Student Attitudes towards a Totally Smoke Free University Campus. BMC Public Health, 13, 738. https://doi.org/10.1186/1471-2458-13-738

[39] Saunders, J.B., Aasland, O.G., Babor, T.F., de la Fuente, J.R. and Grant, M. (1993) Development of the Alcohol Use Disorders Identification Test (AUDIT): Who Collaborative Project on Early Detection of Persons with Harmful Alcohol Consumption-II. Addiction, 88, 791-804. https://doi.org/10.1111/j.1360-0443.1993.tb02093.x

[40] Kypri, K. and Langley, J.D. (2003) Perceived Social Norms and Their Relation to University Student Drinking. Journal of Studies on Alcohol, 64, 829-834. https://doi.org/10.15288/jsa.2003.64.829

[41] Roche Ann, M. and Kerrianne, W. (1999) Drinking and University Students: From Celebration to Inebriation. Drug and Alcohol Review, 18, 389-399. https://doi.org/10.1080/09595239996257

[42] Burns, S., Crawford, G., Hallett, J., Jancey, J., Portsmouth, L., Hunt, K. and Longo, J. (2015) Consequences of Low Risk and Hazardous Alcohol Consumption among University Students in Australia and Implications for Health Promotion Interventions. Open Journal of Preventive Medicine, 5, 1-13. https://doi.org/10.4236/ojpm.2015.51001

[43] Burns, S., Jancey, J., Crawford, G., Hallett, J., Portsmouth, L. and Longo, J. (2016) A Cross Sectional Evaluation of an Alcohol Intervention Targeting University Students. BMC Public Health, 16, 610. https://doi.org/10.1186/s12889-016-3314-4

[44] Rickwood, D., George, A., Parker, R. and Mikhailovich, K. (2011) Harmful Alcohol Use on Campus: Impact on Young People at University. Youth Studies Australia, 30, 34-40.

[45] Kypri, K., Hallett, J., Howat, P., McManus, A., Maycock, B., Bowe, S. and Horton, N.J. (2009) Randomized Controlled Trial of Proactive Web-Based Alcohol Screen- 
ing and Brief Intervention for University Students. Archives of Internal Medicine, 169, 1508-1514. https://doi.org/10.1001/archinternmed.2009.249

[46] Terry, D.J. and Hogg, M.A. (1996) Group Norms and the Attitude-Behavior Relationship: A Role for Group Identification. Personality \& Social Psychology Bulletin, 22, 776-793. https://doi.org/10.1177/0146167296228002

[47] Lee, R.M. and Robbins, S.B. (1995) Measuring Belongingness: The Social Connectedness and the Social Assurance Scales. Journal of Counseling Psychology, 42, 232241. https://doi.org/10.1037/0022-0167.42.2.232

[48] Portney, L.G. and Watkins, M.P. (1993) Foundations of Clinical Research: Applications to Practice. Appleton \& Lange, Norwalk.

[49] Kessler, R.C. (1979) Stress, Social Status, and Psychological Distress. Journal of Health and Social Behavior, 20, 259-272. https://doi.org/10.2307/2136450

[50] Kypri, K., Langley, J., McGee, R., Saunders, J. and Williams, S. (2002) High Prevalence, Persistent Hazardous Drinking among New Zealand Tertiary Students. Alcohol and Alcoholism, 37, 457-464. https://doi.org/10.1093/alcalc/37.5.457

[51] Kypri, K., Paschall, M.J., Langley, J., Baxter, J., Cashell-Smith, M. and Bourdeau, B. (2009) Drinking and Alcohol-Related Harm among New Zealand University Students: Findings from a National Web-Based Survey. Alcoholism: Clinical and Experimental Research, 33, 307-314. https://doi.org/10.1111/j.1530-0277.2008.00834.x

[52] Butler, A.B., Dodge, K.D. and Faurote, E.J. (2010) College Student Employment and Drinking: A Daily Study of Work Stressors, Alcohol Expectancies, and Alcohol Consumption. Journal of Occupational Health Psychology, 15, 291. https://doi.org/10.1037/a0019822

[53] Rosenthal, D.A., Russell, J. and Thomson, G. (2007) Social Connectedness among International Students at an Australian University. Social Indicators Research, 84, 71-82. https://doi.org/10.1007/s11205-006-9075-1

[54] Rosenthal, D.A., Russell, J. and Thomson, G. (2008) The Health and Wellbeing of International Students at an Australian University. Research in Higher Education, 55, 51-67. https://doi.org/10.1007/s10734-006-9037-1

[55] American College Health Association (2007) American College Health Association-National College Health Assessment Spring 2007 Reference Group Data Report (Abridged). Journal of American College Health, 56, 469-479.

[56] Ward, B.W.M.A. and Gryczynski, J. (2007) Alcohol Use and Participation in Organized Recreational Sports among University Undergraduates. Journal of American College Health, 56, 273-280. https://doi.org/10.3200/JACH.56.3.273-280

[57] Brenner, J. and Swanik, K. (2007) High-Risk Drinking Characteristics in Collegiate Athletes. Journal of American College Health, 56, 267-272. https://doi.org/10.3200/JACH.56.3.267-272

[58] O’Brien, K.S., Ali, A., Cotter, J.D., O'Shea, R.P. and Stannard, S. (2007) Hazardous Drinking in New Zealand Sportspeople: Level of Sporting Participation and Drinking Motives. Alcohol and Alcoholism, 42, 376-382. https://doi.org/10.1093/alcalc/agm035

[59] Joyce, H.D. and Early, T.J. (2014) The Impact of School Connectedness and Teacher Support on Depressive Symptoms in Adolescents: A Multilevel Analysis. Children and Youth Services Review, 39, 101-107.

[60] Bond, L., Butler, H., Thomas, L., Carlin, J., Glover, S., Bowes, G., et al. (2007) Social and School Connectedness in Early Secondary School as Predictors of Late Teenage Substance Use, Mental Health, and Academic Outcomes. Journal of Adolescent Health, 40, e9-e18. 
[61] Yang, F., Tan, K.A. and Cheng, W.J.Y. (2014) The Effects of Connectedness on Health-Promoting and Health-Compromising Behaviors in Adolescents: Evidence from a Statewide Survey. Journal of Primary Prevention, 35, 33-46. https://doi.org/10.1007/s10935-013-0327-y

[62] Haslam, C., Cruwys, T., Haslam, S.A., Dingle, G. and Chang, M.X.-L. (2016) Groups 4 Health: Evidence That a Social-Identity Intervention That Builds and Strengthens Social Group Membership Improves Mental Health. Journal of Affective Disorders, 194, 188-195.

[63] Berends, L., Jones, S.C. and Andrews, K. (2015) Adolescent Drinking, Social Identity, and Parenting for Safety: Perspectives from Australian Adolescents and Parents. Health \& Place, 38, 22-29.

[64] Rodkin, P.C. (2004) Peer Ecologies of Aggression and Bullying. In: Espelage, D.L. and Swearer, S.M., Eds., Bullying in American Schools. A Social-Ecological Perspective on Prevention and Intervention, Lawrence Erlbaum Associates, Mahwah.

[65] Barry, A.E., Howell, S., Bopp, T., Stellefson, M., Chaney, E., Piazza-Gardner, A., et al. (2014) A Field-Based Community Assessment of Intoxication Levels across College Football Weekends: Does It Matter Who's Playing? The Journal of Primary Prevention, 1-8.

\section{Submit or recommend next manuscript to SCIRP and we will provide best service for you:}

Accepting pre-submission inquiries through Email, Facebook, LinkedIn, Twitter, etc. A wide selection of journals (inclusive of 9 subjects, more than 200 journals)

Providing 24-hour high-quality service

User-friendly online submission system

Fair and swift peer-review system

Efficient typesetting and proofreading procedure

Display of the result of downloads and visits, as well as the number of cited articles

Maximum dissemination of your research work

Submit your manuscript at: http://papersubmission.scirp.org/

Or contact ojpm@scirp.org 